\title{
Mandatory financial reporting processes and outcomes
}

\begin{abstract}
In an extension to the mandatory financial reporting literature, we consider compliance and applicability as intermediate stages in the disclosure decision process, and investigate to what extent these measures explain any variance in the quantity of disclosure. We use financial instruments disclosures as our empirical context because of the level of complexity and diversity of the mandatory requirements. We find that neither applicability nor compliance show statistically significant association with disclosure quantity. By contrast we find that a firm's financial instruments management programme is an important determinant of both applicability and quantity. Finally, we demonstrate the economic consequences of applicability, compliance and quantity through their association with audit fees. For companies that use financial instruments management programmes to a greater extent, audit fees are higher. In contrast, the quantity of financial instruments disclosures appears to reduce audit fees.
\end{abstract}

Key words: Applicability; Compliance; Quantity; Financial instruments; Financial reporting; Audit fees. 


\section{Introduction}

The vast literature concerning the important question of 'what incentivizes companies to reveal information' (see reviews by Healy and Palepu, 2001; Verrecchia, 2001; Leuz and Wysocki, 2008; Beyer et al., 2010) is under-theorized in a mandatory setting (Glaum et al., 2013). Despite claims that managerial discretion is limited when making mandatory disclosure decisions (e.g. Verrecchia, 2001), empirical studies consistently find incomplete compliance (Tsalavoutas, 2011; Hassan et al., 2008; Lopes and Rodrigues, 2007), seemingly facilitated by imperfect enforcement (Brown and Tarca, 2005; Daske et al., 2008) and driven by country-specific factors and voluntary incentives to disclose information (e.g. Street and Gray, 2002; Glaum, et al., 2013).

Using financial instruments reporting as a research context, the purpose of this article is to address a gap in the literature that does not differentiate the predisclosure process from the reporting outcome. We explore three inter-related dimensions of this problem: applicability; compliance; and the quantity of information revealed. Through an examination of financial instruments reporting amongst the sample of 58 FTSE100 non-financial firms, we pursue three specific research objectives. First, we ask what affects the applicability of, and compliance with, International Financial Reporting Standard 7 Financial Instruments:

Disclosures (2005) (hereafter, IFRS 7). Second, we consider how applicability and compliance, alongside the extent of a company's financial instruments management programme, affect the quantity of financial instruments disclosures. Third, we examine the economic effects of the mandatory disclosure process and outcome. After controlling for known determinants, we estimate the effects on audit 
fees of: (i) a company's financial instruments management programme; (ii) the applicability of IFRS 7 disclosures; (iii) compliance with IFRS 7 disclosures; and (iv) the quantity of information disclosed under IFRS 7 requirements.

In contrast to prior mandatory disclosure work, we start from the basis that accounting standards require a company to explain the results of its investing, operating and financing policies and decisions. Some elements of this process remain unaddressed. This paper seeks to understand the relationship between firm-specific attributes, the process, the reporting outcome and the economic consequences of that outcome. We specify four identificatory stages of the disclosure process as a motivation for our empirical hypotheses, namely: Is the specific requirement applicable? If so, will the company comply? How much information should be disclosed in relation with a requirement? What are the economic consequences of this decision?

We adopt the following approach. First, we propose that the nature and complexity of a firm's financial instruments management programme will be captured by the level of applicability; where applicability is defined as the number of IFRS 7 requirements which the firm is obliged to adhere. Second, compliance levels measured in relation to what is applicable are determined by the incentives to disclose information (e.g. Street and Gray, 2002; Glaum, et al., 2013). In turn, the level of applicability and the level of compliance should determine the quantity of information. However, despite identical levels of applicability, some companies may have more to disclose because of the nature of their business. Further, we question whether the incentives to voluntarily disclose information may be more (less) important as a determinant of quantity when the applicability levels are low 
(high). Finally, we question whether the value of financial instruments and/or the quantity of financial instruments disclosures have a complementary or substitute effect on audit fees.

We find the following. First, the overall size of the firm and the extent of financial instruments management programmes are statistically positively related to the applicability of IFRS 7 . Jointly, the following explain $58 \%$ of the variability in applicability: size, value of total non-derivative financial instruments, risk exposure measured as the fair value of derivative financial instruments (hereafter 'derivatives') disclosed, and whether a firm uses derivatives for speculation or hedging. We adopt these four proxies to measure the extent of a firm's financial instruments management programme. Second, and contrary to our expectations, we find that applicability and compliance are not significant determinants of quantity. However, size and holdings of derivatives are significantly positively related to the quantity of disclosure. The four proxies we adopt for financial instruments management programme (listed above) explain about $25 \%$ of the variability in quantity. Third, we find that audit fees are statistically and economically positively associated with the value of non-derivative financial instruments with one standard deviation increase in financial instruments leading to $27 \%$ increase in audit fees. This is partially consistent with the notion that a premium is required to compensate for the effort. However, audit fees are not associated with derivatives nor whether a firm uses derivatives for speculation or hedging purposes. Finally, we find a negative association between audit fees and the quantity of financial instruments disclosures. This relation is economically important as one percentage point increase in the quantity of disclosure results in 
one half of one percent decrease in audit fees. This may appear inconsistent but it suggests that the audit fee premium can be reduced by a managerial decision to reduce information asymmetry. These results are robust to alternative estimation procedures. Overall, these results confirm the important role of managerial choice in the disclosure decision-making process.

Our study contributes to the mandatory disclosure literature in several ways. Firstly, we shift the focus from compliance as the final outcome of the disclosure process (e.g. Street and Gray, 2002; Glaum, et al., 2013) to compliance as an additional intermediate stage that might explain various levels of disclosure. Secondly, while the compliance literature uses applicability as an instrument to calculate compliance, we introduce it as an important factor related to levels of disclosure. Thirdly, we propose that the disclosure decision needs to be considered alongside any related policies and decisions, such as financial strategy. Fourthly, our study contributes to the disclosure literature by providing further evidence that the variability in the quantity of disclosed information is not associated with the variability in compliance or applicability (Roulstone, 1999; Dunne et al., 2004; Chalmers, 2001; Miihkinen, 2012; Bischof, 2009). Fifthly, the identification of these three distinct factors is a useful addition to the study of mandatory financial reporting (e.g. Lopes and Rodrigues, 2007; Bischof, 2009; Al-Akra et al., 2010; Birt et al., 2013). Sixthly, our measure of compliance is far more detailed than in related studies (Lopes and Rodrigues, 2007; Birt et al., 2013), which results in a finer measurement of compliance, and as such could be useful in other research contexts. The trade-off resultant from this more granular measurement approach is a smaller sample. Finally, to the best of our knowledge, no prior study has 
empirically tested the association between audit fees and either the value of financial instruments or the quantity of financial instruments disclosures.

The remainder of the paper is organized as follows. Section 2 presents a brief background, a review of the literature and hypothesis development. Section 3 outlines the research design, sample and methods. Section 4 discusses the results. Finally, Section 5 provides a summary and conclusion.

\section{Motivation and related literature}

The compliance literature fails to address a number of fundamental questions concerning process and outcome. First, there is an over-reliance on disclosure checklists as the outcome measure of compliance and disclosure without due consideration of the interaction between variability in compliance and the levels of applicability and disclosure quantity. Second, there is not enough attention paid to the related managerial choices, policies and strategies that drive movements in assets (liabilities) or gains (losses) which underpin the disclosure. Third, the implications of voluntarism in a mandatory setting are rarely taken into account. We briefly expand on these three issues below.

With respect to the first concern, checklists can be used to measure compliance (e.g. Lopes and Rodrigues, 2007; Al-Akra et al., 2010; Tsalavoutas, 2011). A recent study by Glaum et al. (2013) finds substantial non-compliance with IFRS 3 and IAS 36 across 17 European countries. These findings may be explained by unintentional neglect (when management overlook particular requirements) or misinterpretation of disclosure rules (e.g. managers conclude that certain requirements do not apply). Intentional neglect is more likely to occur in the 
event of imperfect enforcement (e.g. Brown and Tarca, 2005; Daske et al., 2008). Any observed variability in compliance levels might be explained by a company's incentives to disclose (Glaum et al., 2013). Yet, using compliance checklists as an outcome variable does not provide a complete explanation of what a company is doing and why it is doing it (Beretta and Bozzolan, 2004 is a notable exception). The index-based approach also does not measure what the company should and/or might disclose. Furthermore, compliance, applicability and quantity might be related but the association has not previously been tested.

In terms of the economic effects of disclosure, mandatory disclosures have been shown to be the most used and the most useful sections of the annual report (e.g. Vergoossen, 1993; Chang and Most, 1985). The primary benefits of providing information are the reduction of information asymmetry and the mitigation of the adverse selection problem (Healy and Palepu, 2001; Verrecchia, 2001). Voluntary disclosure can reduce the cost of capital (Botosan, 1997, 2006), increase liquidity (Leuz and Verrecchia, 2000), and reduce the risk premium (Jorgensen and Kirschenheiter, 2003). However, silence or omission is a signal that the company is "withholding... potentially relevant information from the capital markets" (Glaum et al., 2013, p.164).

Bringing these two strands together - i.e. determinants of compliance and disclosure consequences - our challenge is that companies may demonstrate the same proportionate level of compliance, but the disclosure might be substantially different in volume, scope and technical content. Such diverse disclosure may have different economic consequences (i.e. audit fees). 
As for applicability, we draw on Heitzman et al.'s (2010: 109) argument that if an item is material, there is a perceived "duty to disclose" even in the absence of a reporting requirement. Heitzman et al. (2010) focus on the concept of materiality in a voluntary setting. We transform this and introduce the notion of applicability in its place; noting that the two concepts overlap. Additionally, while Heitzman et al. (2010) focus on materiality in the decision to disclose a single item (advertising expenses), we consider applicability in the context of multiple requirements within an accounting standard.

To address the second concern regarding the range of managerial choices, policies and strategies that drive movements in assets (liabilities) or gains (losses) which underpin the disclosure, we focus on the nature of the business undertaken as a determinant of the disclosure process and disclosure outcome. The importance of context on the disclosure decision is not completely new to the literature. For example, the ICAEW wrote (2000, p. 14) "risk can only be appreciated in the broader context of a company's strategy", and Beretta and Bozzolan (2004: 269) claimed that 'the reporting of risk must... consider information on strategy, actions, and performance in addition to information specifically focused on risk. We propose that companies are likely to have different approaches and strategies for managing their financial instruments, and as a result they will have different disclosure process options under IFRS 7.

We use financial instruments reporting because it is an inviting context to study these issues. Furthermore, we contest that it is important to look at the financial instruments management programme as a determinant of the level of financial instruments disclosure. Financial instruments information is of critical 
importance to users seeking to achieve a balanced understanding of a company's position and performance (e.g. Gebhardt, 2012; Chernenko and Faulkender, 2012; Chalmers and Godfrey, 2004; Chalmers, 2001) ${ }^{1}$. Evidence suggests that the disclosures are informative (e.g. Campbell et al., 2011; Seow and Tam, 2002) and yet the area remains under-explored (Gebhardt, 2012). The mandatory financial instruments disclosure requirements are extensive and allow considerable scope for variability (Bischof, 2009; Hassan et al., 2008; Lopes and Rodrigues, 2007; Woods and Marginson, 2004; Chalmers and Godfrey, 2004; Chalmers, 2001).

This brings us to the third concern, i.e. that the implications of voluntarism in a mandatory setting are rarely taken into account. The nature and choices surrounding financial instruments reporting is complex and controversial (Gebhardt 2012). Consequently, the final disclosure outcome (in this case, quantity), might have a variable economic effect across companies. We extend prior literature by examining if financial instruments disclosures convey information about the quantity and quality of risk management activities for companies, which in turn impact audit fees as a consequence of altered perceptions of audit risk. On the one hand, auditors might demand an audit fee premium to compensate for the additional effort required to audit financial instruments. On the other hand, greater levels of financial instruments disclosures might improve the information environment and reduce information asymmetry (e.g. Horton et al., 2013). If an improvement in the information environment reduces the audit risk premium, audit

\footnotetext{
${ }^{1}$ Note that whilst derivative financial instruments constitute less than $10 \%$ of the value of the average firm in our sample (cf. Guay and Kothari, 2003), the value of the broader sub-category 'financial instruments' make up almost $53 \%$.
} 
fees might be negatively associated with the level of financial instruments disclosures.

We bring together these three research questions together in a four-stage approach in Figure 1 and throw light upon the effectiveness of accounting regulations and the potential benefits of improved disclosure and enforcement mechanisms. Taken together, in this framework, a company's financial instruments management programme appears as an important input in guiding disclosure process through applicability and compliance and in determining quantity, as well as a direct determinant of audit fees. Additionally, a lower (higher) quantity of disclosure may reduce (increase) the audit effort and, consequently, reduce (increase) audit fees. Details of related hypotheses are outlined in section 3.

[Insert Figure 1 about here]

\section{Hypotheses development}

\subsection{Hypotheses: Determinants of applicability, compliance and quantity of disclosure}

This first set of hypotheses examine what determines the three primary dimensions under review: applicability; compliance; and quantity. In applying IFRS 7, management's first task is to evaluate which requirements are applicable. The main considerations are: whether the underlying item where disclosure is required exists, and whether the item is material due to its size or nature. We predict that the financial instruments management programme is positively related to the levels of applicability. For example, firms that manage interest rate risk using interest rate swaps will be obliged to apply requirements related to derivatives and possibly hedge accounting, while firms who do not engage in derivatives-based risk 
management programmes will not. This leads to our first hypothesis ( $\mathrm{H} 1$ direction in Figure 1):

H1: The overall applicability level of requirements under IFRS 7 increases in line with a company's financial instruments management programme.

The second decision in the disclosure process is whether to comply with the applicable requirements. In an imperfect enforcement environment, certain reporting incentives influence compliance. Management will have incentives to disclose the required and applicable information under IFRS 7 if the perceived net benefits of disclosure are positive (e.g. Botosan, 1997, 2006 [cost of capital advantage]; Leuz and Verrecchia, 2000 [increased liquidity]; Jorgensen and Kirschenheiter, 2003 [impact on risk premium]). Therefore, we examine if the proxies for disclosure incentives play a role in explaining the variability in compliance ( $\mathrm{H} 2$ direction in Figure 1).

H2: Higher level of compliance with IFRS 7 requirements is positively associated with the incentives to disclose information.

After the two process issues are resolved (i.e. applicability and compliance), an outcome-oriented decision needs to be made. Management must decide how much information to disclose. In a full compliance environment, one would expect that a company that needs to disclose more items because of their applicability, would disclose more in volume terms. Similarly, for the same level of applicability one would expect that a company that has a higher level of compliance would disclose more in volume terms. Thus, we assume that any additional requirement that is applicable and complied with will contribute to a higher quantity of disclosure (H3 direction in Figure 1). 
H3: The quantity of disclosure is positively associated with levels of applicability and compliance.

As stated in $\mathrm{H} 1$, we expect that the nature and scope of a company's financial instruments management programme will affect applicability. In turn, the level of applicability is likely to affect the quantity of disclosure. However, even where companies' levels of applicability (and compliance) are the same, the volume may vary. This leads to our fourth hypothesis ( $\mathrm{H} 4$ direction in Figure 1$)$.

$\mathrm{H} 4$ : The quantity of disclosure is positively associated with the nature and complexity of a company's financial instruments management programme.

\subsection{Hypotheses: Economic impact of the quantity of financial}

\section{instruments and financial instruments disclosures}

The aim of the second set of hypotheses is to understand the economic impact of the quantity of financial instruments and financial instruments disclosures. Financial instruments disclosures are complex and controversial (Gebhardt, 2012; Bamber and McMeeking, 2016). The demand for audits is assumed to be the efficient solution to costly contracting problems where the company's accounting technology, risk management systems and corporate governance mechanisms are components of the nexus of contracts (Watts and Zimmerman, 1986). Auditors provide assurance as to the integrity of the accounting numbers produced by the company's accounting technology (Simunic, 1980). It is well established that there is heterogeneity in companies' exposures to risk and appetites to manage these exposures through financial instruments (e.g. Grant and Marshall, 1997). Some types of financial instruments (e.g. payables) are less complex and easier to audit than others (e.g. credit default swaps). As such, 
we question whether the quantity and complexity of financial instruments management programme is positively associated with audit fees. We contend that accounting firms will charge a fee premium to firms with large amounts of financial instruments because of the additional effort required to audit these items.

H5a: Companies with large financial instruments programmes are likely to pay higher audit fees than companies with small financial instruments programmes.

Next we examine whether the level of disclosed information might affect audit fees through an improvement in the information environment. It is claimed that increased corporate disclosure levels can reduce information asymmetry and the cost of capital (Botosan 1997). If the quantity of financial instruments disclosures improves the information environment, this ought to reduce audit risk, and hence the audit premium. Taking these factors into consideration, our hypothesis is:

$\mathrm{H} 5 \mathrm{~b}$ : The quantity of financial instruments disclosures is likely to decrease the level of audit fees.

\section{Research design and methods}

\subsection{Sample}

This study reviews the IFRS 7 disclosures for the FTSE-100 non-financial firms for years beginning on or after 1 January 2007. We consider only the largest firms for our sample because the data collection process is an enormously timeconsuming and challenging exercise that requires hand collection and checking of 133 (as set out in IFRS7) potential items for each observation, many of which are complex in nature and lengthy (e.g. derivatives). In addition, the analysis is set in a 
single jurisdiction to avoid methodological issues associated with various institutional factors and enforcement regimes. Furthermore, we focus only on firmspecific determinants of the disclosure process (applicability and compliance), reporting outcome (quantity of disclosure) and the consequences of this disclosure decision on audit fees because all firms are exposed to the same institutional factors and enforcement regime.

We choose year 2007 for our sample period because it covers the initial period of IFRS 7 implementation. This first-year of adoption is likely to show the highest level of variance in disclosure compliance and quantity, although we recognise that IFRS 7 has 28 new requirements while 105 are transferred from its predecessor, i.e. IAS 32.

The original sample included 76 non-financial companies, of whom, 10 did not report before a substantial amendment was passed in October 2008 that altered the Standard ${ }^{2}$. Of the remaining 66 firms, full data was only available for 58 . We focus on non-financial firms because their financial instruments disclosures are under-studied (Gebhardt, 2012). We exclude financial firms because they typically build their business models around holding, exchanging and trading financial instruments (e.g. Woods and Marginson, 2004). For instance, a small number of large financial institutions hold a dominant share (>90\%) of the market for derivative financial instruments and control over-the-counter dealing (e.g. Sinkey Jr. and Carter, 2000). Instead, non-financial firms predominately use them to manage straightforward transaction and economic risk exposure (e.g. Géczy,

\footnotetext{
2 IFRS 7 was effective for years commencing on or after 1 January 2007. Therefore, we used this amendment as the cut-off for our sample.
} 
Minton, and Schrand, 1997). Evidence of speculation amongst non-financial firms is limited ${ }^{3}$ as evidenced by the Wharton surveys undertaken by Bodnar and colleagues e.g. Bodnar, Hayt, Marston and Smithson (1995). In turn, the regulators require financial firms to provide higher levels of disclosure to comply with codes of best practice (e.g. Basel) which go beyond the requirements of IFRS 7. In addition they have put in place stricter supervisory and monitoring arrangements. ${ }^{4}$

Our sample is biased towards the largest, most established firms on the London Stock Exchange (LSE). This bias may affect our results in two ways. Economically, the largest LSE firms operate in a rich disclosure and regulatory environment resulting in small variation among these most scrutinized firms. For this reason, as we show in Table 3, we find generally high levels of compliance and low variability in compliance (if not in quantity of disclosed information).

Econometrically, the small sample reduces the power of our tests. Nevertheless, our findings are important because it is likely that the observed results present the lower magnitude bound compared with the case in which the wider sample of firms would have been included. As pointed out in Leuz and Verrecchia (2000) and Lang, Lins and Maffett (2012), the importance of disclosure and transparency is more pronounced for smaller firms that operate in low disclosure environments. Similarly, we are careful to note that findings which reject hypotheses cannot be generalised to the wider universe of firms.

\footnotetext{
${ }^{3}$ Chernenko and Faulkender (2012) show evidence of hedging and speculation amongst nonfinancial firms. They suggest that this may be strongest when firms' executive compensation contracts are more performance sensitive. We keenly await further evidence to support this thesis. ${ }^{4}$ See Bischof (2009) for an analysis of bank financial instruments disclosures following the introduction of IFRS 7.
} 


\subsection{Measurement of applicability, compliance and quantity variables}

Our study focuses on the disclosure process (applicability and compliance) and outcomes (quantity). Various measures have previously been adopted to capture the volume of disclosure. In the case of measuring quantity, Milne and Adler (1999) provided a critique of the importance of the unit of analysis. Findings suggest, however, that empirical results are similar regardless of the approach taken (Hackston and Milne, 1996). We take the number of words as the measure of quantity. As this measure is right-skewed, we use natural logarithm of the number of words in our regression tests (Miihkinen, 2012). Accuracy checks were manually performed for ten of the companies and these showed immaterial levels of variation $(<0.05)$.

To measure compliance and applicability, a checklist was completed ${ }^{5}$. This required checking the annual report disclosure for each firm for compliance with IFRS 7's 133 separate requirements. The scoring index was unweighted and dichotomous. Information appropriately disclosed and required was marked as '1', information not disclosed but required ' 0 '6, and information not required ' $N / A$ '. Where there was information voluntarily disclosed over and above IFRS 7 requirements, this was separately noted but did not feature in the above scoring mechanism. Our applicability measure (APPL) is then the proportion of total IFRS 7 requirements applicable and our compliance measure (COMPL) is the proportion of IFRS 7 requirements applicable and appropriately met.

\footnotetext{
${ }^{5}$ Available on request.

${ }^{6}$ Note, immaterial issues such as spelling and grammar mistakes were not considered to be cases of non-compliance.
} 
There are rare occasions when making applicability decisions becomes a challenging aspect, in particular when accounting for materiality. In the majority of cases, it is reasonably straightforward to award a score of ' 1 ', ' 0 ' or ' $N / A$ ' because the requirement is either relevant to the company, or not. However, an item might be deemed immaterial by an entity and therefore no disclosure will be provided; but as non-disclosure is a private decision, a judgement must be made by the coder whether to mark the checklist ' 0 ' or ' $N / A^{\prime}$ '.

There were simple cases where omitted disclosures could be measured as 'required but not provided' according to a quantitative scale (e.g. using simple measures such as $<5 \%$ of profit before tax). However, there are subjective areas and the decision becomes less formulaic. In rare cases, it is necessary to cede to the judgement of the company and mark the non-disclosure as ' $N / A$ '. Before this notation was blindly recorded, however, the financial statements were reviewed for evidence of supporting and corroborating evidence. ${ }^{7}$

A common problem with content analysis is the reliability of the results (Krippendorff, 2004). To help mitigate this, inter-coder reliability testing was undertaken for ten of the companies to ensure the results were robust. The Kappa coefficients ranged from $\mathrm{k}=0.97$ to $\mathrm{k}=1.00$ thus indicating high levels of accuracy, stability and reproducibility.

\subsection{Research design}

\footnotetext{
${ }^{7}$ For example, if a company provided no information about their management of market risk, the Operating and Financial Review was reviewed alongside any other likely triggers of market risk, for example commodities or derivatives trading, and assess whether this risk was material in nature. If sufficient evidence exists that this was purposeful non-disclosure then the registered result would be ' 0 ' rather than ' $N / A$ '.
} 


\subsubsection{Empirical models}

To test hypotheses $\mathrm{H} 1$ to $\mathrm{H} 4$ we run the following regression models:

$\mathrm{H} 1$

$$
A P P L_{i}=\alpha_{0}+\sum_{j=1}^{4} \beta_{j} \text { FIMANPROG }_{i}+\varepsilon_{i}
$$

$\mathrm{H} 2$

$$
\operatorname{COMPL}_{i}=\alpha_{0}+\sum_{j=1}^{4} \chi_{j} D I S C L I N C_{i}+\varepsilon_{i}
$$

$\mathrm{H} 3$ and $\mathrm{H} 4$

$$
\text { QUAN }_{i}=\alpha_{0}+\lambda_{1} A P P L_{i}+\lambda_{1} \text { COMPL }_{i}+\sum_{j=1}^{4} \beta_{j} \text { FIMANPROG }_{i}
$$

$$
+\sum_{j=1}^{4} \chi_{j} \operatorname{DISCLINC} C_{i}+\varepsilon_{i}
$$

$\mathrm{H} 5 \mathrm{a} \& \mathrm{H} 5 \mathrm{~b}$

$$
L A F_{i}=\alpha_{0}+\lambda_{1} \mathrm{QUAN}_{i}+\sum_{j=1}^{3} \beta_{j} \text { FIMANPROG }_{i}+\sum_{j=1}^{14} \delta_{j} \mathrm{CONTROLS}_{i}+\varepsilon_{i}
$$

where subscript $i$ is a specific company; APPL is applicability level, COMPL is compliance, QUAN is quantity of disclosure, LAF is the natural logarithm of audit fees, FIMANPROG is a list of variables representing the financial instruments management programme, DISCLINC is a list of variables representing the incentives to voluntarily disclose information, and CONTROLS are other variable known to be associated with audit fees. The variables used to represent FINMANPROG and DISCLINC are defined in section 4.3.2. ${ }^{8}$ Audit fees as well as controls variables are defined in section 4.3.3.

\footnotetext{
${ }^{8}$ We also conducted testing of models in which, in addition to the above variables, we controlled for industry indicators to capture the effect of the industry-specific nature of the business operations and disclosures. The direction of the results is qualitatively similar and none of our main conclusions change. We do not include industry dummies in our main tests as the addition of seven industry variables would reduce the power of our regression tests given our small sample size. For example, in telecommunications, there are only two firms and only four firms are in healthcare. The results are available on request.
} 
To test $\mathrm{H} 5 \mathrm{a}$ and $\mathrm{H} 5 \mathrm{~b}$ we include FIMANPROG and QUAN, as well as control variables that capture known audit fee determinants. As SIZE is known to be the strongest predictor of audit fees from previous literature, in this context FIMANPROG is captured only by FI, RISKEXP and HEDGE. We test H1, H2, H3 and $\mathrm{H} 4$ first using OLS and then assume the observed values represent measured variables using Structural Equation Modelling (Path Analysis) techniques.

Structural equation models are a broad set of mathematical and statistical methods that allow one to relax the assumption of linearity and instead fit networks of constructs to data. Path analysis is particularly useful in this context because we rely on measurement instruments for some key observable variables (e.g. APPL, COMPL, QUAN) to test hypotheses on unobservable constructs. The specification of input and output paths used in this technique allows us to test both direct effects and indirect effects of variables. The hypothesis $\mathrm{H} 5$ is tested using OLS, and as robustness tests, other techniques to control for endogeneity (see section 5.4 for details).

\subsubsection{Independent variables representing FIMANPROG and DISCLINC}

\section{in the regression tests}

The variables used as proxies for a financial instruments management programme (FIMANPROG) are: relative size of financial instruments $(\mathrm{FI})$, the total size of the company (SIZE), risk exposure of the company (RISKEXP) and whether the firm is using financial instruments for speculation or risk-management purposes (HEDGE). FI, SIZE and HEDGE are likely to be associated with the scope and complexity of the financial management programme of the company, while 
RISKEXP should measure the financial risk exposure of the company that should be managed.

$\mathrm{FI}$ is the sum of cash and cash equivalents, trade receivables, other investments, trade payables and short and long-term debt divided by total assets. We do not include derivatives in this variable, as derivatives are accounted for separately. SIZE is the natural logarithm of total assets. We use the sum of total derivative assets and liabilities relative to size as the proxy for the firm's risk exposure (RISKEXP). Given the context, it is important to differentiate between those companies that hedge and those that speculate. We therefore develop the variable 'HEDGE' by identifying 'speculators' (1), as distinct from hedgers (0). We determine the former as those firms who meet one or more of the following criteria: (i) the firm discloses that it uses financial instruments for speculative purposes; (ii) the firm discloses - qualitatively or quantitatively - an active material financial instruments trading programme from which it derives a separate stream of revenues distinct from its core business; (iii) the firm has material gains (losses) arising from financial instruments designated as derivatives 'held for trading'.

Although the level of derivatives may appear low (cf. Guay and Kothari, 2003; Gebhardt, 2012), these instruments are positively associated with a company's exposure to various financial risks - interest rate risk, forward exchange risk, commodity risk, and so forth - before hedging is taken into account (Bartram et al., 2011). Another advantage of using derivatives in the context of an

\footnotetext{
${ }^{9}$ Further details available on request.
} 
applicability determinant is that they are directly related to one of the financial items that is required to be disclosed.

As for disclosure incentives (DISCLINC) variables, we follow the extant literature. Companies with higher levels of information asymmetry have a greater incentive to disclose as this theoretically reduces the cost of capital (adverse selection). We proxy for information asymmetry using several variables, as follows. It may be reflected in the annual volume of shares traded relative to the number of shares that are outstanding. It may also increase if a firm issues equity, and increase where the share price is more volatile (e.g. Marshall and Weetman, 2007; Lang and Lundholm, 1993).

To reduce information asymmetry and perceived agency costs from moral hazard, firms are thought to disclose more. Agency costs of debt are proxied by leverage (e.g. Marshall and Weetman, 2007; Dobler et al., 2011), liquidity measured by the current ratio (Marshall and Weetman, 2007) - and the level of closely held shares (Glaum et al., 2013). However, the existence of other sources of information may reduce pressure on companies to disclose information in their annual reports. Therefore, there may be a negative relationship between the number of analysts following a firm (e.g. Lang and Lundholm, 1996; Irani and Karamanou, 2003) and the number of news items about the firm in the press (e.g. Chalmers and Godfrey, 2004).

In line with other studies we investigate whether profitability is a determinant of compliance and quantity. We note that the direction of any relationship is uncertain. There is an argument that more profitable companies are inclined to disclose more (Lang and Lundholm, 1993), but more disclosure may drive higher 
proprietary costs (Heitzman et al., 2010), and may also expose poorly performing companies to higher levels of litigation risk (Skinner, 1994). The latter points indicate an inverse relation between profitability and disclosure. In addition, following Chalmers and Godfrey (2004), we use an indicator variable for firms in the oil and mining industry, as these firms may be exposed to higher commodity risk, and therefore disclose more.

The number of variables is large and this could reduce the power of the regression tests. Therefore we eliminate insignificant variables to obtain a more parsimonious model. The final model includes volume of shares traded (VOLUME), number of analysts following the firm (AF), gearing (LEV) and current ratio (CR) as proxies for disclosure incentives (DISCLINC). For details of the procedure and rationale, see Appendix. A list of definitions of all variables used is presented in Table 1.

[Insert Table 1 about here]

\subsubsection{Independent variables representing audit fee determinants in the} audit fee tests

There is an extensive audit pricing literature, launched by the seminal work of Simunic (1980). A standard set of variables has emerged that are known to control for the main drivers of audit fees - client size, complexity and client risk (e.g. Simunic, 1980; McMeeking et al., 2006). The natural logarithm of audit fees and the natural logarithm of total assets (client size) are commonly used to reduce the degree of skewness. Variations in client risk are captured by the ratio of long term debt to total assets (LEV), current ratio (CR), quick ratio (QUICK), inventories to assets (INVENTORIES), sales growth (GROWTH) and receivables to total 
assets (RECEIVABLES). The square root of the total number of subsidiaries (SUBSID) and the ratio of the number of foreign subsidiaries to total number of subsidiaries (FOREIGN) capture audit complexity. The dichotomous auditor change variable (SWITCH) captures the learning curve effect on the first year of engagement. The dichotomous indicator variable (' 1 ' if the company's year-end is December, ' 0 ' otherwise) captures the busiest period in the auditors' calendar year (BUSY). The percentage of shares held by the board of directors (BID), number of board meetings (MEET) and the percentage of shares owned by "substantial shareholdings" (SO) capture corporate governance factors thought to influence audit fees. Although additional variables are advocated by some scholars (see Hay et al., 2006 for a summary), the aforementioned variables produce robust results that explain the majority of the variation in audit fees across a variety of jurisdictions and time settings.

\section{Empirical results}

\subsection{Descriptive statistics}

There is management discretion due to the broadness of the Standard's scope and this might contribute to disclosure variability. IFRS 7 has 34 balance sheet disclosure requirements, a further 10 relate to the income statement and equity, 49 relate to risk, 2 relate to adoptions and exemptions, and there are 38 other requirements (Table 2). The 133 requirements can be further broken down as: 57 hard-rules, 47 soft-rules $^{10}$, and 29 principles (Table 3: Panel A).

\section{[Insert Table 2 about here]}

\footnotetext{
10 Hard rules provide guidance as to what is permissible in advance whereas soft rules require judgement to be employed.
} 
The principles-based requirements cover sensitive issues such as market, credit, and liquidity risk, which will differ between entities and periods of account according to idiosyncratic policies and decisions. Most of these requirements are inherited from its immediate predecessors $(105)^{11}$, while the remainder (28) are new (Table 3: Panel B).

[Insert Table 3 about here]

Table 4 presents descriptive statistics of the main variables. The mean level of applicability (APPL) is $58.3 \%$, which is similar to its median. No firm was obliged to meet all the requirements of IFRS 7 ; indeed, the firm with the highest applicability score was required to meet approximately three-quarters (99 requirements).

\section{[Insert Table 4 about here]}

The compliance level is high (mean: 94.6\%) which, after adjusting for applicability, shows that the average firm fails to comply with around four of IFRS 7 's requirements. ${ }^{12}$ The standard deviation of compliance is $5.8 \%$ suggesting low variability. The level of compliance is higher than in comparable studies (e.g. Glaum et al., 2013 [73\%]; Tsalavoutas, 2011 [<90\%]; Hassan et al., 2008 [33\%]; Lopes and Rodrigues, 2007 [44\%]). Explanations for this high compliance rate might be that our sample comprises the largest firms, in a developed stock market, with strong corporate governance mechanisms, alongside managerial experience

\footnotetext{
11 IAS 30 Disclosures in Financial Statements of Banks and Similar Financial Institutions, IAS 32 Financial Instruments: Presentation and IAS 39 Financial Instruments: Recognition and Measurement.

12 This is obtained by multiplying number of requirements (133) with mean applicability (0.583) and non-compliance $(1-0.946)$.
} 
of applying IAS' 32 and 39, in a time of heightened anxiety given the challenging economic context (financial crisis), and the use of the services of the Big 4 audit firms. The average number of words (quantity) is 2,993 ( $\min : 1,085$; max: 7,542 ; standard deviation: 1,374). This highlights a considerable variation in quantity between firms. The average (maximum) audit fee of £3.759M (£25.7M) are similar to other studies and not unsurprising given the data are from the largest 100 companies in the UK. Skewness falls after taking the natural logarithm and there is reasonable variation in LAF across the sample.

Considering the independent variables in our tests, it is interesting to note that financial instruments (excluding derivatives) $(\mathrm{FI})$ are about half the total assets on average and the fair value of derivatives (RISKEXP) represents around $3.5 \%$ of total assets. In a similar vein, Guay and Kothari (2003) find that only $56.7 \%$ of 1,000 US non-financial firms used derivatives. This led them to the conclusion that 'corporate derivatives use appears to be a small piece of non-financial firms' overall risk profile" (p.423). The level of derivatives in our study is similar to that reported in Gebhardt (2012) for STOXX Europe 600 firms in the 2001-2009 period of $2.86 \%$. At first glance, these magnitudes may seem small to warrant the inclusion of derivatives as a proxy for financial risk exposure. However, variations in market conditions as well as managerial policies and decisions, imply that these instruments have the power to be economically significant and materially affect a company's position and performance (as seen many times before e.g. Enron, WorldCom, etc.). Furthermore, the use of derivatives is important to determining IFRS 7 disclosure and applicability given the number of requirements related 
thereto. ${ }^{13}$ In our sample, 12 firms $(20.7 \%)$ are identified to use financial instruments for speculative purposes (HEDGE variable).

\subsection{Correlation analysis}

Correlation analysis allows us to analyse univariate relations between variables and provides a preliminary view of the validity of our hypotheses (Table 5). For the sake of brevity, we do not include full set of predictors of audit fees as the majority of these variables are known to predict audit fees from previous literature and do not form part of the specifications of other tests. First, we note that only correlations higher than 0.20 in absolute amounts are statistically significant, both for Pearson and Spearman correlations. In line with H1, APPL is positively correlated with SIZE (Pearson coefficient of 0.665 and Spearman of 0.669 ), RISKEXP (Pearson coefficient of 0.512 and Spearman of 0.612) and HEDGE (Pearson coefficient of 0.266 and Spearman of 0.316 ). However, APPL is not statistically significantly correlated with FI. COMPL is not statistically significantly correlated to any of the proxies for disclosure incentives, contrary to H2. QUAN is significantly positively correlated with both APPL (Pearson coefficient of 0.448 and Spearman of 0.510 ) and COMPL (Pearson coefficient of 0.326 and Spearman of 0.355) in line with our hypothesis, $\mathrm{H} 3$. We also find that QUAN is significantly positively correlated with SIZE and RISKEXP, in line with H4. FI is significantly and positively correlated with LAF, and QUAN is significantly and negatively correlated with LAF.

[Insert Table 5 about here]

${ }^{13}$ For example, there are 12 requirements that relate to hedging alone. 
Within the group of independent variables, there is a high positive correlation between FI and LEV of 0.609 (Pearson) and 0.629 (Spearman). This is because these two variables share an important variable in the numerator - shortand long-term debt. In line with previous literature, SIZE is strongly positively correlated with AF and negatively correlated to VOLUME and CR. AF is negatively correlated to $\mathrm{FI}$, and LEV to CR. Unsurprisingly, HEDGE is positively correlated with FI and RISKEXP. Other correlations between independent variables are statistically insignificant.

\subsection{Tests of hypotheses on determinants of applicability, compliance}

\section{and quantity of disclosure}

Table 6 presents the regression results for the relation between applicability and proxies for financial instrument management programmes (FIMANPROG): FI, SIZE, RISKEXP and HEDGE. Univariate regressions (models 1, 2, 3 and 4) demonstrate the positive relation of APPL with SIZE, RISKEXP and HEDGE, but not with FI. Multivariate OLS regressions (model 5) demonstrate that these four variables explain $58 \%$ of the variability in applicability. Estimation using the SEM technique (model 6) does not materially change the results for SIZE, RISKEXP, FI and HEDGE.

The effects of SIZE, RISKEXP and HEDGE on APPL are economically significant. In a joint model, i.e. 5, an increase in one standard deviation of SIZE (corresponding to roughly tripling of total assets) leads to a 3.7 percentage points 
increase in APPL, which is around $56 \%$ of a standard deviation of APPL. ${ }^{14}$ An increase of one standard deviation in RISKEXP leads to a 2 percentage point increase in APPL, approximately one third of its standard deviation. If a company uses derivatives for speculative purposes, instead for risk management, the APPL increases in 3.2 percentage points, or roughly $50 \%$ of its standard deviation. These results are consistent with $\mathrm{H} 1$, when SIZE, RISKEXP and HEDGE are considered, but not consistent when $\mathrm{Fl}$ is considered.

[Insert Table 6 about here]

Table 7 presents the regression results for the relation between compliance and disclosure incentives (DISCLINC): VOLUME, AF, LEV and CR. We find that variables proxying for disclosure incentives are not related to compliance (Model 1). Jointly, they explain only around $7 \%$ or variability in COMPL and none of them are significant. This is unsurprising given the descriptive statistics pertaining to COMPL (i.e. high compliance, low standard deviation). Unreported results remain almost identical when we control for APPL and proxies for FIMANPROG, with a modest increase in $R^{2}$ but negative adjusted $R^{2}$. Therefore, we do not find support for $\mathrm{H} 2$.

\section{[Insert Table 7 about here]}

Table 8 presents results regarding the association between the quantity of disclosures and applicability, compliance, and proxies for financial instrument management programmes. Firstly, we regress QUAN on disclosure incentives as

\footnotetext{
${ }^{14}$ We obtained this effect by multiplying the standard deviation of size (1.147) with the coefficient of 0.032 which gives 0.037 . As the standard deviation of APPL is 0.065 , the ratio $0.037 / 0.065$ is approximately 0.56 or $56 \%$. The same procedure is applied for RISKEXP.
} 
the benchmark model (Model 1). VOLUME, AF, LEV, and CR explain $26 \%$ of the variability in QUAN. QUAN is statistically significantly related with VOLUME and LEV at the $5 \%$ level. Secondly, we regress QUAN only on APPL and COMPL individually and jointly (Models 2 to 4 ) to test H3. Individually, APPL and COMPL have a statistically positive association with QUAN, explaining $20 \%$ and $11 \%$ of the variability respectively. In the joint regression, both coefficients on APPL and COMPL are positive (2.744 and 1.943) and significant at the $5 \%$ level, respectively explaining around $26 \%$ of variability in QUAN. The magnitude of the effect is also significant. An increase in one standard deviation of APPL (COMPL) is associated with an $18 \%(12 \%)$ increase in QUAN.

[Insert Table 8 about here]

Regressions presented in models 5 to 8 test our hypothesis $\mathrm{H} 4$ regarding the relation between FIMANPROG and QUAN. The results show that SIZE and RISKEXP are statistically positively related to QUAN explaining individually $17 \%$ and $13 \%$ of the variability in QUAN (models 6 and 7 ), while the coefficient on FI and HEDGE is statistically insignificant (models 5 and 8 ). Jointly, these four FIMANPROG proxies explain $25 \%$ of variability in QUAN, with SIZE and RISKEXP remaining statistically significant (model 9).

It is possible that the relationship between APPL and COMPL with QUAN may be driven by omitted variables. Therefore, it is necessary to see whether the positive association of APPL and COMPL with QUAN stands after controlling for FIMANPROG as the determinant of APPL. In model 10, therefore, we include APPL, COMPL, as well as proxies for FIMANPROG and controls for DISCLINC. Both APPL and COMPL coefficients significantly reduce in size relative to model 4 
and become statistically insignificant from zero. The decrease in the coefficient is particularly dramatic for APPL: from the estimated 2.744 in model 4 to 0.457 in model 10. By contrast, SIZE and RISKEXP as the proxies for FIMANPROG remain significant at the $5 \%$ level, with SIZE having similar magnitude comparing to model 9 and the coefficient on RISKEXP reduced. The results for SIZE and RISKEXP are economically significant. The coefficients of 0.137 indicate that an increase of one standard deviation in SIZE is associated with an increase of around one third of standard deviation of QUAN. As for RISKEXP, the coefficients of 1.956 indicate that an increase of one standard deviation in RISKEXPL is associated with an increase of around one fifth of standard deviation of QUAN. The model 10 explains $50 \%$ of the variability in QUAN. Results from path analysis are very similar to those in Table 10.

One potential concern is that FIMANPROG variables and QUAN respond to similar underlying economic factors. For example, risky firms with aggressive sales growth may face higher credit and liquidity risk which is reflected in higher level of FIMANPROG variables, and, independently of FIMANPROG, in higher disclosure quantity. As a consequence, the effect of FIMANPROG on QUAN could be biased upwards because of this correlated omitted variable issue. To alleviate this endogeneity concern we employ instruments that are likely to affect the second stage variable only through their effect on the endogenous variables. We instrument statistically significant FIMANPROG in OLS tests in Table 8 (SIZE and RISKEXP) using industry-median SIZE, and RISKEXP, respectively. The p-values are both marginally significant at the $10 \%$ level. We ascertain the appropriateness of instrumental variables estimation using the Hausman (1978) test of whether the 
IV estimator is significantly different from the OLS estimator. The Hausman (1978) test statistic $(p=0.24)$ suggests that correlated omitted variables are not a concern in this specification.

Overall, results are consistent with $\mathrm{H} 4$ but not with $\mathrm{H} 3$. APPL ceases to be associated with QUAN once proxies for FIMANPROG are included. In other words, FIMANPROG is so strong a determinant of APPL and QUAN that the remaining variance of $A P P L$, once controlled for FIMANPROG, has a negligible effect on QUAN. ${ }^{15}$

\subsection{Tests of hypotheses on financial instruments management} programme, applicability, compliance and quantity of disclosures on audit fees

Table 9 presents the results of the tests concerning the economic effects of financial instruments management programme and financial instruments disclosures on audit fees. Similar to prior studies, SIZE, SUBSID, FOREIGN, and BUSY (at the $5 \%$ level) plus RECEIVABLES and MEET (at the 10\% level) explain a large proportion of the variability in audit fees. In this setting, the proxies for FIMANPROG include only FI, RISKEXP and HEDGE. SIZE is used as a control variable because the previous literature firmly establishes SIZE as a most important determinant of audit fees, and consequently it cannot be interpreted only as a proxy for FIMANPROG. In a joint model that includes all three FIMANPROG

\footnotetext{
15 In additional tests (not reported) we find that financial instruments management programme and disclosure incentives explain $80 \%$ of disclosure quantity when the level of applicability is below median and only $47 \%$ of disclosure quantity when the level of applicability is above median, in line with Heitzman et al. (2010) conjencture that disclosure incentives are more important in mandatory environment when materiality thresholds are low.
} 
proxies and QUAN (column 5 of Table 9), and partially consistent with H5a, we observe a statistically significant positive association between LAF and $\mathrm{FI}$, but not between LAF and RISKEXP nor between LAF and HEDGE.

The economic effect of FI on audit fees is important - an increase of one standard deviation in FI leads to $27 \%$ increase in audit fees. This implies auditors charge a premium to firms with large amounts of financial instruments to compensate them for the additional risk required to audit these complex financial instruments. QUAN is significantly and negatively associated with audit fees in a full model (column 5 of Table 9), consistent with H5b. The economic effect is important: one percent increase in quantity of disclosure reduces audit fees by around one half of one percent. Allowing for the additional risk associated with firms that have large amounts of non-derivative financial instruments $(\mathrm{FI})$, this finding suggests that the quantity of financial instruments disclosures (QUAN) can reduce the audit risk premium and this is conferred to the company by reduced fees. These results indicate that lower fees might be the result of disclosures reducing information asymmetry and improving the information environment, but we leave tests of this exact mechanism for future research.

[Insert Table 9 about here???]

A potential limitation in interpreting OLS results is that the quantity of disclosure and audit fees may be endogenously determined. In the context of this paper, managers do not make financial instruments management programme decisions randomly, but on the basis of expectations on how their choices will influence disclosures, and how these in turn might affect economic outcomes. For example, in order to reduce audit fees managers may choose simpler financial 
policies, which would translate into simpler disclosure and, consequently, lower audit effort and audit fees. By contrast, in distressed firms the level of nonderivative financial instruments might be large and requires more auditor attention. Thus, a negative association between FI and LAF found in the OLS regression could be wrongly attributed to the level of financial instruments rather than the higher riskiness of the firm. As for the relation between disclosure quantity and audit fees, after controlling for the level of financial instruments, it seems that managers with low proprietary costs may choose a strategy of higher transparency because more disclosures appear to reduce audit fees. In this setting, the effect of proprietary costs on audit fees through disclosure could be erroneously attributed to the substitute effect of quantity on disclosure, in so much as it reduces information asymmetry.

To deal with the endogeneity, we introduce a two-stage least squares regression in which the level of non-derivative financial instruments and quantity of disclosure variables are instrumented. We use the industry median of the level of non-derivative financial instruments and the industry median of quantity of disclosure to instrument FI and QUAN, respectively. As unobservable distress and proprietary costs are arguably firm-specific attributes, industry medians reflect exogenous industry differences in levels of $\mathrm{FI}$ and QUAN, while being orthogonal to distress and proprietary costs. As such, they are likely to affect the second-stage audit fee variable only through their influence on the endogenous variables, QUAN and FI. Industry-median QUAN and industry-median FI are calculated using the sample of non-financials from the FTSE100 index. Industries are defined at a 
broad level to ensure that there are sufficient (more than three) observations in each sector (and avoid small sample sector-level econometric issues).

We initially compute the predicted values of QUAN and FI by estimating first-stage regressions in which QUAN and FI are the dependent variables and the independent variables include all the exogenous variables from the second stage regression and the chosen instruments. We then use the predicted values of QUAN and FIMANPROG as independent variables instead of their actual values in the second stage regression using the following specification:

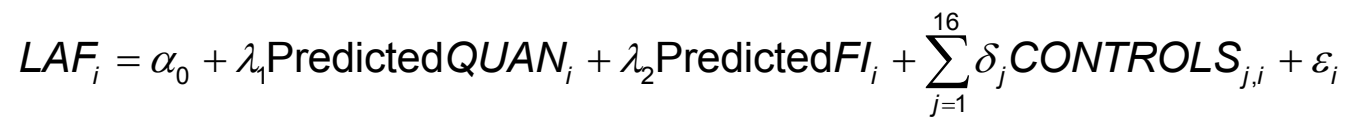

Controls include ten predictors of audit fees from Table 9 plus two proxies for FIMANPROG not significant in Table 9 (RISKEXP and HEDGE).

We report the results of the first-stage and second-stage regressions with associated test statistics in Table 10. We tested our instruments against a barrage of relevance (correlation with the endogenous variable) and validity (orthogonality to the residual) conditions. Firstly, the coefficient of each instrument must be statistically significant in the first stage regressions because this indicates that the instruments are relevant. Secondly, the F-statistic associated with every endogenous variable must be statistically significant, thus indicating that the instruments selected are jointly relevant. The coefficient on industry-median FI (0.657) and industry-median QUAN (0.635) are significant at the $1 \%$ level in the first stage regressions. Moreover, the $\mathrm{F}$ statistics for the endogenous variables exceed 10 , partial F-statistic exceeds 2 , and both are statistically significant. The 
Hausman (1978) test statistic $(F=11.34)$ is significant at the $1 \%$ level, suggesting the existence of an endogeneity issue.

The coefficient on Predicted FI is 1.196 and Predicted QUAN is -0.512 , which are both significant at the $5 \%$ level, and the coefficients are very similar to those obtained in the OLS regressions. In summary, regardless of the methodology we adopt to control for endogeneity, we find a statistically and economically significant relation between audit fees, FI and QUAN.

[Insert Table 10 about here??]

\section{Summary and conclusions}

This study examines the determinants of applicability, compliance and quantity of financial instruments disclosures as well as the economic effects of disclosure on audit fees. In a departure from prior studies, we consider both compliance and applicability as the intermediate stages of the disclosure process that might explain overall levels of disclosure. We focus on the role of financial instruments management programmes as the determinant of applicability and quantity of disclosures.

Following this we look at the differences in applicability and compliance across the nature of information, the type of disclosure and the length of past use of requirements. This is a timely and relevant study given the poor current state of knowledge regarding non-financial firms' financial instruments disclosures (Gebhardt, 2012).

We find a strong positive relation between applicability and (a) size, (b) the level of total derivative assets and liabilities to total assets and (c) the extent of 
speculative activities, but the association with the relative size of financial instruments (d) is insignificant. These four variables explain about $58 \%$ of the variability of applicability in our sample.

We completed a full IFRS 7 compliance review for non-financial firms in the FTSE 100 for years commencing on or after 1 January 2007. We found relatively high levels of compliance (e.g. Tsalavoutas, 2011; Hassan et al., 2008; Lopes and Rodrigues, 2007). Given this, it is unsurprising that we are not able to detect any significant determinants of compliance in our regression tests. Nevertheless, we do not find that ignorance or misinterpretation (Glaum et al., 2013) have a significant impact on compliance.

As for the determinants of quantity of disclosure, we do not find a statistically significant relation between applicability or compliance with quantity after controlling for disclosure incentives. By contrast, size and the level of total derivative assets and liabilities to total assets are statistically and economically significantly positively related to quantity.

Financial instruments are economically significant in two distinct ways. First, accounting firms charge an audit firm premium to companies that have high levels of non-derivative financial instruments to compensate them for the additional time and resource needed to provide assurance about these complex instruments. Second, one percent increase in the amount of financial instruments disclosures is associated with around one half of one percent lower audit fees. We conjecture that the lower audit risk premium finding might be due to reductions in information asymmetry and improvements in the information environment that are captured within the audit risk premium. This is a potentially fruitful area of future research. 
This study is amongst the first to consider the importance of the link between the mandatory disclosure process (applicability and compliance) and the disclosure outcome (comprehensiveness of disclosure measured by quantity) as well as to investigate firm-specific determinants related to financial instruments management programmes other than voluntary disclosure incentives. The results show the first-order importance of financial instruments management programmes for the applicability and comprehensiveness of disclosure, as well as the limited role that attributes of the disclosure process contribute to the quantity. The findings also indicate potentially important economic impact of disclosure on reducing audit fees.

As all studies, ours suffers from certain limitations. First, our sample is small. While this should work against us finding support for our hypotheses due to power issues, future research may extend the sample to mid-sized and smaller companies, which would also carry the benefit of incorporating more medium- and small-sized audit firms into the sample. In addition, future research may consider this link in the cross-country context and the interaction between institutions, compliance and disclosure outcome, as the previous studies have focused only on the role of institutions shaping compliance (Glaum et al., 2013). Second, we also mainly look at an early stage of adoption of the accounting standard and we cannot provide insights on whether and how disclosure practices patterns change over time, within industries or countries. Finally, our study raises important questions about managerial discretion in a mandatory financial reporting setting, and this subject requires urgent attention. Intervention seems to happen at the compliance 
and quantity levels, and we show the implications of this variability on audit fees. We urge future researchers to consider alternative measures of economic impact.

\section{References}

Al-Akra, M., Eddie, I., \& Ali, M. (2010). The influence of the introduction of accounting disclosure regulation on mandatory disclosure compliance: Evidence from Jordan. British Accounting Review, 42 (3), 170-186.

Bamber, M. \& McMeeking, K. (2016). An examination of international accounting standard-setting due process and the implications for legitimacy. British Accounting Review, 48(1), 59-73.

Bartram, S.M., Brown, G.W. \& Conrad, J. (2011). The effects of derivatives on firm risk and value. Journal of Financial and Quantitative Analysis, 46 (4), 967-999.

Beretta, S., \& Bozzolan, S. (2004). A framework for the analysis of firm risk communication. International Journal of Accounting, 39(1), 265-288.

Beyer, A., Cohen, D. A., Lys, T. Z., \& Walther, B. R. (2010). The financial reporting environment: Review of the recent literature. Journal of Accounting \& Economics, 50(2), 296-343.

Birt, J., Rankin, M. \& Song, C.L. (2013). Derivatives and use of financial instrument disclosure in the extractives industry. Accounting \& Finance, 53(1), 55-83.

Bischof, J. (2009). The effects of IFRS 7 adoption on bank disclosure in Europe. Accounting in Europe, 6(2), 167-194.

Bodnar, G. M., Hayt, G. S., Marston, R. C., \& Smithson, C. W. (1995). Wharton survey of derivatives usage by US non-financial firms. Financial Management, 104114.

Botosan, C. A. (1997). Disclosure level and the cost of equity capital. Accounting Review, 72(3), 323-349.

Botosan, C. (2006). Disclosure and the cost of capital: what do we know? Accounting and Business Research, (36 Special Issue: International Accounting Policy Forum), 31-40. 
Brooks, C. (2008). Introductory econometrics for finance. Cambridge University Press.

Brown, P., \& Tarca, A. (2005). A commentary on issues relating to the enforcement of International Financial Reporting Standards in the EU. European Accounting Review, 14(1), 181-212.

Bushman, R.M., Piotroski, J.D. \& Smith, A.J. (2004). What determines corporate transparency? Journal of Accounting Research, 42(2), 207-252.

Campbell, J. L., Chen, H., Dhaliwal, D. S., Lu, H. M., \& Steele, L. B. (2011). The information content of mandatory risk factor disclosures in corporate filings. Review of Accounting Studies, 19(1) 1-60.

Chalmers, K. (2001). The progression from voluntary to mandatory derivative instrument disclosures-look who's talking. Australian Accounting Review, 11(23), 34-44.

Chalmers, K., \& Godfrey, J.M. (2004). Reputation costs: the impetus for voluntary derivative FI reporting. Accounting, Organizations and Society, 29(2), 95-125. Chang, L.S., \& Most, K.S. (1985). The perceived usefulness of financial statement for investors' decisions, International University Press, Miami.

Chernenko, S., \& Faulkender, M. (2012). The two sides of derivatives usage: Hedging and speculating with interest rate swaps. Journal of Financial and Quantitative Analysis, 46(06), 1727-1754.

D'Souza, J., Ramesh, K., \& Shen, M. (2010). Disclosure of GAAP line items in earnings announcements. Review of Accounting Studies, 15(1), 179-219.

Daske, H., Hail, L., Leuz, C., \& Verdi, R. (2008). Mandatory IFRS reporting around the world: Early evidence on the economic consequences. Journal of Accounting Research, 46(5), 1085-1142.

Dobler, M., Lajili, K., \& Zéghal, D. (2011). Attributes of corporate risk disclosure: An international investigation in the manufacturing sector. Journal of International Accounting Research, 10(2), 1-22.

Dunne, T., Helliar, C., Power, D., Mallin, C., Ow-Yong, K.E.A.N., \& Moir, L. (2004). The introduction of derivatives reporting in the UK: A content analysis of FRS 13 disclosures. Journal of Derivatives Accounting, 1(02), 205-219. 
Gebhardt, G. (2012). Financial instruments in non-financial firms: what do we know? Accounting and Business Research, 42 (3), 267-289.

Géczy, C., Minton, B. A., \& Schrand, C. (1997). Why firms use currency derivatives. The Journal of Finance, 52(4), 1323-1354.

Glaum, M., Schmidt, P., Street, D. L., \& Vogel, S. (2013). Compliance with IFRS 3and IAS 36-required disclosures across 17 European countries: company-and country-level determinants. Accounting and Business Research, 43(3), 163-204. Grant, K., \& Marshall, A. P. (1997). Large UK companies and derivatives.

European Financial Management, 3(2), 191-208.

Greene, W. H. (1993). Econometric analysis, $2^{\text {nd }}$ edition, Macmillan Publishing Company.

Guay, W., \& Kothari, S. P. (2003). How much do firms hedge with derivatives? Journal of Financial Economics, 70(3), 423-461.

Gujarati, D. (2003). Basic Econometrics. New York: McGraw-Hill. Hackston, D., \& Milne, M. J. (1996). Some determinants of social and environmental disclosures in New Zealand companies. Accounting, Auditing \& Accountability Journal, 9(1), 77-108.

Hassan, M.S., Mohd-Saleh, N., \& Rahman, C., A. (2008). Determinants of Fls disclosure quality among listed firms in Malaysia. Available at SSRN:

http://ssrn.com/abstract=1157788 (accessed 18 March 2010)

Hausman, J. (1978). Specification tests in econometrics. Econometrica, 46 (6), 1251-1271.

Hay, D, Kneckel, R. \& Wong, N. (2006). Audit fees: a meta-analysis of the effect of supply and demand attributes. Contemporary Accounting Research, 23(1), 141191.

Healy, P.M., \& Palepu, K.G. (2001). Information asymmetry, corporate disclosure, and the capital markets: A review of the empirical disclosure literature. Journal of Accounting and Economics, 31(3), 405-440.

Heitzman, S., Wasley, C., \& Zimmerman, J. (2010). The joint effects of materiality thresholds and voluntary disclosure incentives on firms' disclosure decisions. Journal of Accounting and Economics, 49(1), 109-132. 
Horton, J., Serafeim, G., \& Serafeim, I. (2013). Does mandatory IFRS adoption improve the information environment?. Contemporary Accounting Research, 30(1), 388-423.

ICAEW (2000). No surprises: The case for better risk reporting. London: Financial Reporting Committee. Institute of Chartered Accountants in England and Wales. International Accounting Standards Board (2010). Conceptual Framework for Financial Reporting 2010.

International Accounting Standards Board (2005). International Financial Reporting Standard 7 Financial Instruments: Disclosures.

International Accounting Standards Board (2005). International Accounting Standard 32 Financial Instruments: Presentation.

International Accounting Standards Committee (1989). Framework for the Preparation and Presentation of Financial Statements.

Irani, A. \& Karamanou, I. (2003). Regulation Fair Disclosure, analyst following, and analyst forecast dispersion. Accounting Horizons, 17 (1), 15-29.

Jorgensen, B. N., \& Kirschenheiter, M. T. (2003). Discretionary risk disclosures. Accounting Review, 78(2), 449-469.

Krippendorff, K. (2004). Content analysis: An introduction to its methodology. $2^{\text {nd }}$ edition, Sage Publications, Beverley Hills.

Lang, M.H., \& Lundholm, R. (1993). Cross-sectional determinants of analyst ratings of corporate disclosures. Journal of Accounting Research, 31(2), 246-271. Lang, M. H., \& Lundholm, R. J. (1996). Corporate disclosure policy and analyst behavior. Accounting Review, 71(4), 467-492.

Lang, M.H., Lins, K.L. \& Maffett, M. (2012). Transparency, liquidity, and valuation: International evidence on when transparency matters most. Journal of Accounting Research, 50(3), 729-774.

Leuz, C., \& Verrecchia, R. E. (2000). The economic consequences of increased disclosure. Journal of Accounting Research, 38, 91-124.

Leuz, C., \& Wysocki, P.D. (2008). Economic consequences of financial reporting and disclosure regulation: a review and suggestions for future research. Available at SSRN: $\underline{\text { htp: }: / / s s r n . c o m / a b s t r a c t=1105398 ~(a c c e s s e d ~} 2$ February 2011). 
Lopes, P.T., \& Rodrigues, L.L. (2007). Accounting for Fls: an analysis of the determinants of disclosure in the Portuguese stock exchange. International Journal of Accounting, 42(1), 25-56.

Marshall, A., \& Weetman, P. (2007). Modelling transparency in disclosure: the case of foreign exchange risk management. Journal of Business Finance \& Accounting, 34(5-6), 705-739.

McMeeking, K., Peasnell, K. \& Pope, P. (2006). The determinants of the UK big firm premium. Accounting and Business Research, 36(3), 207-232.

Miihkinen, A. (2012). What Drives Quality of Firm Risk Disclosure?: The impact of a national disclosure standard and reporting incentives under IFRS. International Journal of Accounting, 47(4), 437-468.

Milne, M. J., \& Adler, R. W. (1999). Exploring the reliability of social and environmental disclosures content analysis. Accounting, Auditing \& Accountability Journal, 12(2), 237-256.

Pearson, R.W. (2010). Statistical Persuasion, Sage Publications Inc., Thousand Oaks, California

Roulstone, D. T. (1999). Effect of SEC financial reporting release No. 48 on derivative and market risk disclosures. Accounting Horizons, 13(4), 343-363. Seow, G., \& Tam, K. (2002). The usefulness of derivative-related accounting disclosures. Review of Quantitative Finance and Accounting, 18(3), 273-291. Simunic, D. (1980). The pricing of audit services: theory and evidence, Journal of Accounting Research, 18(1), 161-190.

Sinkey Jr., J. F., \& Carter, D. A. (2001). Evidence on the financial characteristics of banks that do and do not use derivatives. The Quarterly Review of Economics and Finance, 40(4), 431-449.

Skinner, D. (1994). Why firms voluntarily disclose bad news. Journal of Accounting Research, 32(1), 38-60.

Street, D. L., \& Gray, S. J. (2002). Factors influencing the extent of corporate compliance with International Accounting Standards: summary of a research monograph. Journal of International Accounting, Auditing and Taxation, 11(1), 5176. 
Tsalavoutas, I. (2011). Transition to IFRS and compliance with mandatory disclosure requirements: What is the signal? Advances in Accounting, 27(2), 390405.

Vergoossen, R.G.A. (1993). The use and perceived importance of annual reports by investment analysts in the Netherlands. European Accounting Review, 2(2), 219-244.

Verrecchia, R. (2001). Essays on disclosure. Journal of Accounting and Economics, 32(1-3), 97-180.

Watts, R., \& Zimmerman, J. (1986). Positive Accounting Theory, Prentice Hall. Woods, M., \& Marginson, D.E.W. (2004). Accounting for derivatives: an evaluation of reporting practice by UK banks. European Accounting Review, 13(2), 373-390. 


\section{APPENDIX}

\section{Issues in the model specification}

One of the limitations of this analysis is the small number of observations measured against a relatively large number of independent variables (Gujarati, 2003). We have identified ten variables that could serve as proxies for disclosure incentives from the literature (DISCLINC). In the model testing hypothesis $\mathrm{H} 3$ and $\mathrm{H} 4$ this sums up to 14 independent variables (excluding APPL and COMPL) with the other four being FI, SIZE, RISKEXP and HEDGE representing FIMANPROG. The small number of degrees of freedom may seriously reduce the power of our tests.

In this extended model with 14 independent variables testing $\mathrm{H} 4$ we find that volume of shares traded (VOLUME), number of analysts following (AF), gearing (LEV) and liquidity (CR) have the highest $t$-statistic of all variables reflecting DISCLINC. In the spirit of general-to-specific methodology (Brooks, 2008) we eliminate sequentially the most insignificant regressors that proxy for disclosure incentives to get a more parsimonious model with the quality of satisfying "encompassing principle", i.e. to get a smaller model capable of explaining all of the results of larger model. Brooks (2008) notes that for small sample sizes this procedure may be impractical if the variables are highly correlated which would lead to switches in significance and magnitude of coefficients after selective deleting of variables. To deal with this problem, we test if there is an issue of multicollinearity. It is believed that if the variance inflation factor (VIF) exceeds 5 then it is possible that multicollinearity will be a serious issue (Pearson, 2010; Gujarati, 2003). Although some of the independent variables show high bivariate correlation (results not tabulated), the highest VIF from the regression model is 2.86. ${ }^{16}$ Therefore, calculations indicated no multicollinearity issues.

Furthermore, four variables significant in the extended model remain significant in the parsimonious model (excluding APPL and COMPL), while no other DISCLINC variable becomes significant. Therefore, it seems that the small sample in this case is not a grave obstacle for applying general to specific

\footnotetext{
${ }^{16}$ Results available on request.
} 
procedure. In addition, the overall explanatory power of the model reduces only slightly, while adjusted $R^{2}$ continuously improves.

Consequently, we include only VOLUME, AF, LEV and CR as DISCLINC variables in the final models testing $\mathrm{H} 3$ and $\mathrm{H} 4$.

In the spirit of Bushman et al. (2004) and D'Souza et al. (2010), we also conducted factor analysis using principal component method to reduce dimensionality. Factor analysis is used to identify and extract common unobservable economic motives of disclosure stemming from different variables rather than using a number of variables that are purported to reflect the same disclosure motive. Four factors are retained using eigenvalue of 1 as a criterion. We rotated the factor using varimax criterion to obtain a clearer pattern of the factor loadings. However, we fail to identify underlying economic disclosure motive of these four factors looking at the individual magnitude of variables' factor loadings. In addition, explanatory power of regressions with four factors as proxies for disclosure incentives is smaller in the case of applicability and quantity as dependent variables and higher in the case of compliance as the dependent variable. For these reasons, we do not present the results from factor analysis. Results are available on request. 